\title{
Triângulos no pentágono: diferentes registros para resolver um problema
}

\author{
Roselene Alves Amâncio \\ André Augusto Deodato
}

\begin{abstract}
Resumo: $O$ objetivo deste artigo é analisar como diferentes formas de registro, utilizadas por estudantes do quinto ano, podem contribuir para a resolução de um problema. Para tanto, organiza-se uma investigação de natureza qualitativa, constituída de três etapas: acesso ao acervo de relatórios das aulas, no âmbito do Projeto de extensão intitulado Descobridores da Matemática; seleção do relatório elaborado sobre a resolução do problema 'Triângulos no pentágono'; reinterpretação da solução comentada nesse relatório. Emerge da análise, empreendida à luz da Teoria da Atividade, a percepção de que houve evolução do 'artefato registro'. Tal percepção resulta do contraste dos diferentes registros dos discentes, produzidos ao longo das aulas que compuseram a unidade analisada. Conclui-se, a partir desse resultado, que a atuação do professor é fundamental para os estudantes fazerem uso do registro não apenas como um protocolo formal, mas sim, como uma ferramenta de auxílio na resolução de problemas.
\end{abstract}

Palavras-chave: Registros dos Estudantes. Anos Iniciais do Ensino Fundamental. Resolução de Problemas. Teoria Histórico-Cultural da Atividade. Educação Matemática.

\section{Triangles in the pentagon: different records to solve a problem}

Roselene Alves Amâncio Doutoranda em Educação pela Universidade Federal de Minas Gerais (UFMG). Professora do Centro Pedagógico da UFMG (CP/UFMG), Belo Horizonte, Minas Gerais, Brasil.

iD http://orcid.org/0000-0001-9118-528X

$\triangle$ roseleneamancio@ufmg.br

André Augusto Deodato Doutorado em Educação pela Universidade Federal de Minas Gerais

(UFMG). Professor da Universidade

Federal de Ouro Preto (UFOP), Ouro Preto, Minas Gerais, Brasil.

http://orcid.org/0000-0003-4323-4010 $\bowtie$ andre.deodato@ufop.edu.br

Recebido em 11/06/2021 Aceito em 23/08/2021 Publicado em 30/10/2021

Abstract: The article issue is to analyze how different forms of recording, used by fifth-year students, can contribute to a solution to a problem. For this purpose, a qualitative investigation is organized, consisting of three stages: access to the collection of reports about lessons, within the scope of extension Project entitled Descobridores da Matemática; selection of the report prepared on the resolution of the 'Triangles in the Pentagon's problem; reinterpretation of the solution commented on in this report. From the analysis, unde rtaken in the light of the Activity Theory, emerges the perception that there was an evolution of the 'recorded artefact'. Such perception results from the contrast of the different records of the students, produced during the classes that made up the analyzed unit. It can be concluded from this result that teacher's role is essential for students to make use of the registry not only as a formal protocol, as well as a tool to aid in problem solving.

Keywords: Student Records. Problem Solving. Early Years of Elementary School. Historical-Cultural Activity Theory. Mathematics Education.

\section{Triángulos en el Pentágono: diferentes registros para resolver un problema}

Resumen: El propósito de este artículo es analizar cómo diferentes formas de registro, utilizadas por los estudiantes de quinto año, pueden contribuir a la resolución de un problema. Por lo tanto, se organiza una investigación cualitativa, que consta de tres etapas: acceso a la colección de informes de clase, en el ámbito del proyecto de extensión titulado Descobridores da Matemática; selección del informe elaborado sobre la resolución del problema 'Triángulos en el Pentágono'; reinterpretación de la solución comentada en este informe. Del análisis, realizado a la luz de la Teoría de la Actividad, surge la percepción de que hubo una evolución del 'artefacto registro'. Tal percepción resulta del contraste de los diferentes registros de los estudiantes, producidos durante las clases que componen la unidad analizada. De este resultado se puede concluir que el rol del docente es fundamental para que los estudiantes hagan uso del registro no solo como un protocolo formal, sino como una herramienta de ayuda en la resolución de problemas.

Palabras clave: Expedientes de estudiantes. Primeros años de la escuela primaria. Solución de problemas. Teoría de la actividad histórico-cultural. Educación Matemática. 


\section{revemop}

\section{Introdução}

Este artigo tem como objetivo principal analisar como diferentes formas de registro, utilizadas por estudantes do quinto ano do Ensino Fundamental, podem contribuir para a construção da solução de um problema. Ao perseguir esse objetivo, não só discutimos a importância da criação coletiva de ideias matemáticas, mas também, encontramos indícios de que uma sala de aula organizada como ambiente, no qual os alunos se sentem à vontade para comunicar suas ideias, colabora para o desenvolvendo dos processos de aprendizagem matemática. Para alcançar o objetivo anunciado, com auxílio de autores da tradição históricocultural (ENGESTRÖM e SANNINO, 2010), delimitamos a atividade (LEONTIEV, 1978) de um grupo de estudantes, caracterizada em aulas de Matemática, como unidade de análise. Além disso, identificamos a referida atividade quando notamos em um grupo de estudantes, a emergência de uma necessidade que os impulsionou ao desenvolvimento de ações coletivas para resolver um problema.

Torna-se imperativo explicar que as aulas de Matemática investigadas ocorreram em uma experiência desenvolvida no projeto de ensino, pesquisa e extensão intitulado Descobridores da Matemática. Tal projeto visa ampliar as oportunidades de discentes - de terceiros, quartos e quintos anos do Ensino Fundamental - se familiarizarem com a resolução de problemas, buscando despertar neles não só o prazer pela aprendizagem da Matemática, mas também, favorecer 0 desenvolvimento de estratégias de resolução de problemas. Além disso, o projeto tem sido realizado, desde o seu início, de forma a contribuir com a formação de futuros professores, ao proporcionar que monitores, alunos da licenciatura em Matemática, desenvolvam conhecimentos teóricos e práticos acerca do ensino de Matemática.

Cabe esclarecer que o projeto, ao optar pela resolução de problemas como metodologia para ensinar Matemática, mostra diálogo com uma tendência da Educação Matemática que vem sendo fortalecida nas últimas décadas e que se encontra em diversas pesquisas (DALTO; SANTOS e BURIASCO, 2017; LOPES, 2013). Mais especificamente, no âmbito do projeto Descobridores da Matemática, assumimos uma concepção de resolução de problemas que se aproxima daquela desenvolvida por Alevatto (2005, p. 41) segundo a qual "uma questão é um problema se o aluno ainda não conhece os meios necessários à resolução, mas está interessado em resolvê-la". Desse modo, no projeto, procuramos propor questões não só com potencial de despertar 0 interesse dos estudantes para resolvê-las, mas também, que demandem deles a elaboração de estratégias para solucioná-las, por não terem uma resposta imediata.

Ainda sobre o projeto Descobridores da Matemática, parece-nos importante destacar que 
os licenciandos que dele participam, se envolvem em diferentes momentos de formação. Tais momentos acontecem em reuniões formação geral (mensais) e em reuniões por equipes (semanais). Uma elucidação necessária é que, no mínimo, um professor da Universidade Federal de Minas Gerais orienta e acompanha o trabalho de cada equipe, nas diferentes tarefas que são realizadas. São exemplos dessas tarefas: seleção, adaptação ou elaboração dos problemas; planejamento das aulas; produção dos relatórios analíticos das aulas.

A investigação aqui relatada se insere no âmbito da pesquisa qualitativa e o percurso metodológico que trilhamos consta de três etapas. Inicialmente acessamos ao acervo de relatórios produzidos coletivamente, por monitores da licenciatura em Matemática e por professores da UFMG. Depois disso, selecionamos um deles, elaborado por ocasião da resolução do problema intitulado "Triângulos no pentágono". A opção por analisar esse relatório se ancora no fato de que ele apresentava uma descrição mais cuidadosa e aprofundada dos detalhes das aulas, comparado aos demais. Tal relatório se caracteriza como uma solução comentada, realizada a partir de uma sequência de aulas de Matemática, na qual um grupo de estudantes do quinto ano se organizou para resolver o problema antes referido. A terceira e última etapa trata-se de um recorte e de uma reinterpretação dessa solução comentada, a partir da lente da Teoria Histórico-Cultural da Atividade (THCA), por meio da qual iluminamos aspectos que não haviam sido abordados anteriormente, sobretudo, discorremos sobre o papel do registro na construção da solução coletiva realizada pelos discentes.

Considerando esse contexto, para alcançar o objetivo estabelecido, organizamos este artigo em quatro seções, da seguinte maneira: apresentamos, depois da introdução, uma seção na qual caracterizamos os principais construtos do referencial teórico-metodológico que fundamenta nossas ideias e que ancora nossos argumentos. Na seção três, trazemos à baila 0 material empírico que será por nós analisado; em seguida, construímos nossa unidade de análise e explicamos como percebemos o papel do registro na atividade 'solução do problema'. Finalizamos, então, o artigo, com uma seção de considerações finais.

\section{A atividade humana na perspectiva histórico-cultural}

Neste artigo, valendo-nos dos referenciais da Teoria Histórico-Cultural da Atividade, adotamos a atividade humana como unidade de análise. Sendo assim, somos impelidos a apresentar ao leitor a interpretação que produzimos para esse conceito que fundamentamos, sobretudo, nos escritos de Lev Vigotski, Alexei Leontiev e Yrjö Engeström. 
Esses teóricos apresentam construtos que não só tem sido reinterpretados de diferentes formas na contemporaneidade e utilizados proficuamente como ferramentas de análise em diversas investigações relacionadas com a Educação Matemática (DAVID; TOMAZ; FERREIRA, 2014; SOUSA, 2020; SOUTO, 2013), como também tais usos têm a legitimidade reconhecida pela comunidade de pesquisa desse campo (LOPES; MARCO, 2015).

É por partilharmos essa compreensão que recorreremos à noção de atividade humana desenvolvida por Leontiev. Ele, um dos colaboradores que deu prosseguimento aos trabalhos de Vigotski, rompe com uma forte tradição da psicologia de sua época - análise da relação do humano com seu objeto de desejo polarizada ou no humano ou no objeto - e, ancorado na dialética marxista, defende que a unidade mais adequada é a atividade que se estabelece entre sujeito e objeto, a partir da mediação de artefatos. Essa ideia inaugurada por Vigotski, recebe de Leontiev contribuições importantes, dentre as quais destacamos duas: i) a defesa de que a atividade humana é coletiva e ii) a caracterização da atividade em três níveis (atividade dirigida ao objeto coletivo; ação dirigida a objetivos parciais; operações influenciadas pelas condições concretas).

Para ilustrar o caráter coletivo e os três níveis da atividade, Leontiev elabora o clássico e recorrente exemplo da caçada, enunciado em diversos trabalhos (CAMPOS, 2018; COSTA, 2016; DEODATO, 2017; LEONTIEV, 1978). Em síntese, para ele, um grupo de pessoas está em uma atividade quando, coletivamente, emerge nesse grupo uma necessidade que mobiliza seus membros na direção de um mesmo objeto. Para tanto, as pessoas desse grupo (sujeitos) distribuem ações individuais - limitadas pelas condições concretas do contexto em que estão inseridas. A realização dessas ações, individualmente não conduz ao objeto, mas, na força do coletivo, tem potencial para saciar a necessidade do grupo. É fundamental compreender que, portanto, tais ações analisadas isoladamente podem não evidenciar uma relação direta da ação do sujeito com o objeto de desejo; reiterando, elas só têm significado quando dirigidas a um fim coletivo.

Essas noções são caras para nossa análise, por duas razões principais. A primeira porque, a nosso ver, é empobrecedor analisar uma situação de sala de aula focando só no aluno ou só na solução por ele apresentada na resolução de um problema; consideramos que é preciso, nesse tipo de análise, procurar os artefatos (que podem ser desenhos, esquemas, material concreto, dentre outros) de que os estudantes lançam mão para alcançar o objeto de desejo. Esse último, em uma sala de aula, pode ser entendido como a apropriação de um determinado conhecimento. 
A segunda é que, quando analisamos as soluções dos alunos, não estamos pensando nelas como ações individuais, apenas; em nossa análise, elas ganham sentido quando entendidas no trabalho coletivo da sala de aula. Por exemplo, neste artigo, lançamos mão desse entendimento, quando discorremos sobre situações em que flagramos estudantes submetendo suas estratégias de registro à apreciação de seus pares e se colocando como apreciadores daquelas elaboradas por eles.

Além da noção de atividade, outro construto fundamental para a argumentação que produzimos é o de artefato. Entendemos esse construto, como enunciado por Costa (2016), a partir da definição apresentada por Cole (1996), defendendo que os artefatos podem ser materiais ou ideais (conceituais). Além disso, concordamos com o destaque de Deodato (2017), para o fato observado por Impedovo, Andreucci e Ginestié (2017), segundo os quais, os artefatos, na perspectiva de Engeström, poderiam "surgir para estabelecer uma simples mediação e evoluir para uma ferramenta mais complexa" (DEODATO, 2017, p.75). Essas ideias são necessárias para a interpretação de que os registros dos estudantes podem ser considerados artefatos de mediação entre eles e o objeto (problema matemático). Além disso, o aprimoramento identificado nas formas de registro pode revelar a evolução 'para uma ferramenta mais complexa', na medida em que os estudantes delas se apropriam.

Por fim, torna-se necessário tanto para a construção da unidade de análise (atividade), quanto para dar visibilidade ao papel do registro (como artefato), informar que nos ancoramos na THCA, tomando emprestado o modelo triangular de Engeström (ENGESTRÖM, 2001). Sobre esse modelo, cujos componentes já foram exaustivamente caracterizados na literatura (DEODATO, 2017; ENGESTRÖM E SANNINO, 2010; SOUSA, 2020), nos limitamos, de um lado, a informar que ele, acrescenta ao modelo vigotskiano (sujeito, artefato, objeto) a chamada base social (regras, comunidade e divisão do trabalho). De outro lado, justificamos o uso desse modelo porque entendemos que ele não só contribui para a organização do material empírico analisado, como também permite que o conceito de artefato seja percebido em diálogo com os princípios fundantes ${ }^{1}$ da THCA.

1 Esses princípios estão descritos detalhadamente em Deodato (2017). 


\section{revemop}

\section{0 contexto da construção de uma solução coletiva}

A experiência aqui descrita foi realizada no colégio de aplicação de uma Universidade Federal, no âmbito de uma disciplina denominada 'Grupo de Trabalho Diferenciado' (GTD). Na organização curricular dessa escola, os GTD constituem-se como oficinas de formato e conteúdo diferenciados, nos quais prevê-se uma organização dos discentes em grupos menores (com, no máximo, 15 estudantes); além disso, neles também são abordadas temáticas diversas. Esse componente curricular possibilita tanto o trabalho com assuntos de interesse dos educandos, quanto a imersão de licenciandos em práticas de ensino, desenvolvidas na escola. A maioria dos GTD é ministrada por estudantes de diferentes cursos de licenciatura que, orientados por docentes do referido colégio de aplicação, planejam e desenvolvem aulas junto aos estudantes do Ensino Fundamental. Assim, desde 2017, em alguns GTD2 desenvolvem-se propostas vinculadas ao projeto Descobridores da Matemática com foco na resolução de problemas com crianças do terceiro, quarto e quinto anos do Ensino Fundamental.

Em uma das aulas do GTD, a professora, uma das autoras deste artigo, apresentou 0 seguinte problema para um grupo de estudantes do quinto ano.

Figura 1: Enunciado do problema

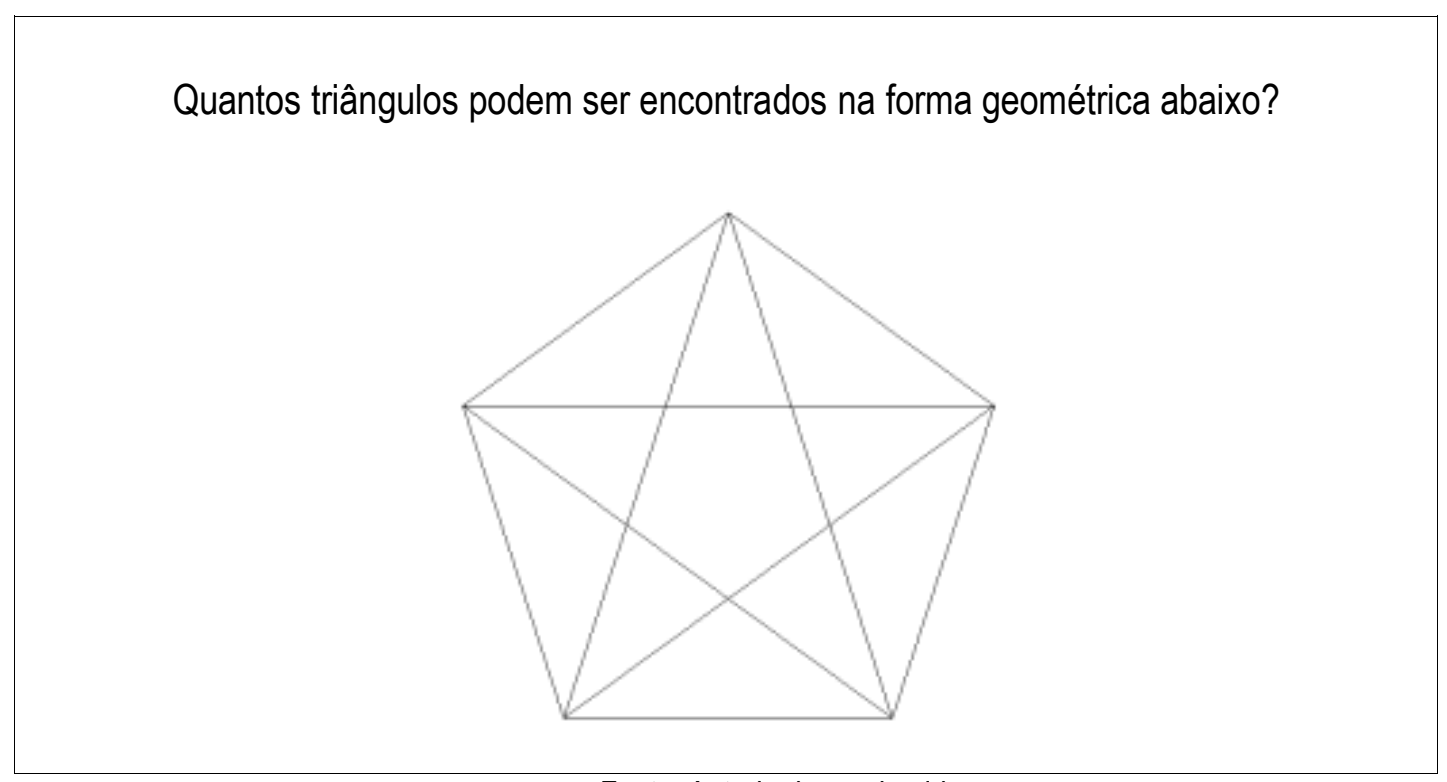

Fonte: Autoria desconhecida.

Depois de a professora realizar a leitura do enunciado, a maioria dos discentes respondeu que, no pentágono, havia 10 triângulos (figura 2). A professora, diante desse cenário, 'provocou' 
os alunos, de um lado, informando que existiam mais que 10 triângulos, de outro incentivando-os a identificarem os outros triângulos, à primeira vista, não percebidos.

Figura 2: Os dez triângulos

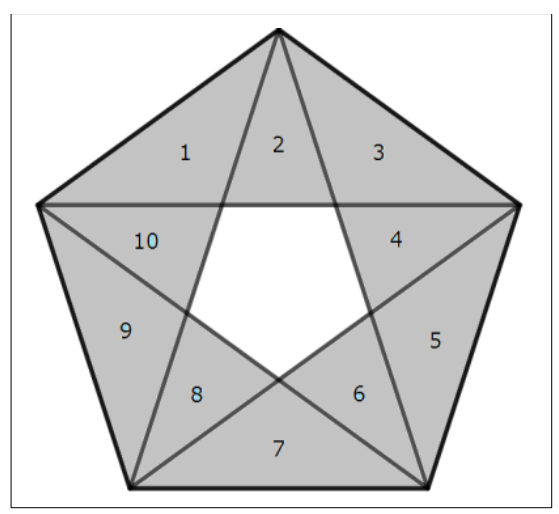

Fonte: Elaborado pelos autores.

Assim, ainda nesse momento inicial, alguns estudantes perceberam que era possível identificar triângulos a partir da composição dos dez triângulos iniciais (figura 3). Uma vez realizada essa conversa inicial, a professora passou o problema como 'dever de casa'3.

Figura 3: Um dos triângulos que poderiam ser identificados por composição

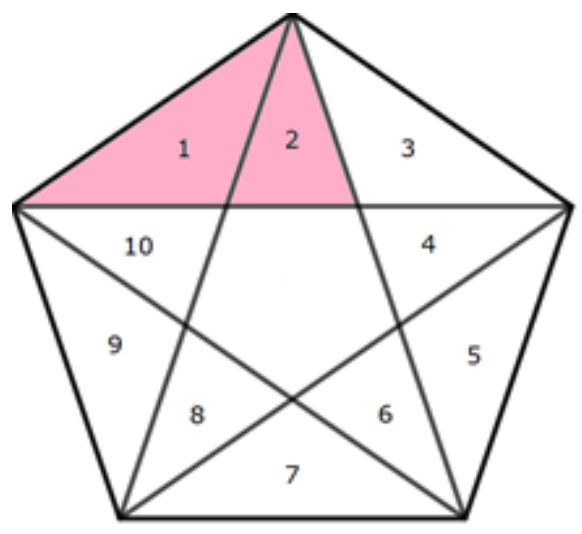

Fonte: Elaborado pelos autores.

$\mathrm{Na}$ aula da semana seguinte, os estudantes foram convidados a apresentar as soluções encontradas para seus pares, em sala de aula. Nessa ocasião, aqueles que se manifestaram, apresentaram quantidades diferentes de triângulos e, no momento da apresentação, foi possível notar que muitos se confundiram e contaram o mesmo triângulo mais de uma vez. Uma primeira

3 Segundo Resende (2012, p.160) os deveres de casa são "atividades escolares a serem realizadas fora do período de aulas e a utilização do espaço doméstico para esse fim". 


\section{revemop}

tentativa de contornar essa duplicidade na contagem foi percebida em um registro que eles produziram que evidenciou o movimento de contornar os triângulos identificados (figura 4).

Figura 4: Estratégia de registro realizada pelo estudante Adair ${ }^{4}$

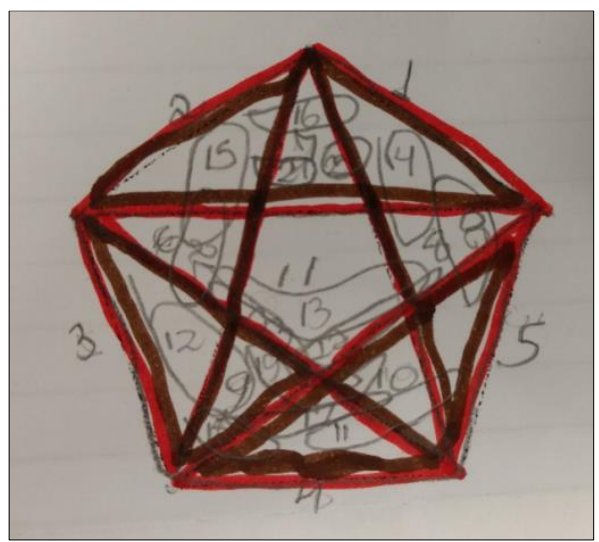

Fonte: Acervo do projeto.

A professora, ao perceber as contagens duplicadas e o registro produzido, de um lado, valorizou a estratégia dos discentes - destacando a importância desse artifício como ajuda para resolver um problema -, de outro, recomendou a eles que tentassem produzir registros mais organizados. Segundo ela, tal recomendação facilitaria a identificação não repetida dos triângulos. Destaca-se, contudo, que ela optou por não indicar uma estratégia como sendo 'a' mais adequada.

A opção da professora pelo debate, por um lado, encontrou alunos que continuaram a lançar mão da estratégia de contornar os triângulos, mantendo-se irredutíveis na defesa de que já tinham encontrado a resposta correta. Por outro lado, o fato de mostrar os triângulos contados mais de uma vez ou indicar triângulos esquecidos pelos alunos, colaborou para, com o tempo, sensibilizar os estudantes para a necessidade de elaborar uma forma de contagem organizada, que evitasse duplicidade ou ausência de triângulos. Essa forma de construir a solução do problema possibilitou o compartilhamento coletivo de estratégias individuais dentre as quais apresentamos, a seguir, cinco.

Iniciamos, destacando uma das formas de registro identificadas. Ela, a nosso ver, sugere que a estudante Hadassa percebeu a necessidade de fazer um tipo de registro que a ajudasse a não se perder no processo de contagem (figura 5). A discente, de início, desenhou e assinalou os dez triângulos não compostos. Depois, sem desenhar todas as diagonais do pentágono, destacou cada triângulo que localizou em uma determinada posição observada.

4 Os nomes dos estudantes são todos fictícios. 


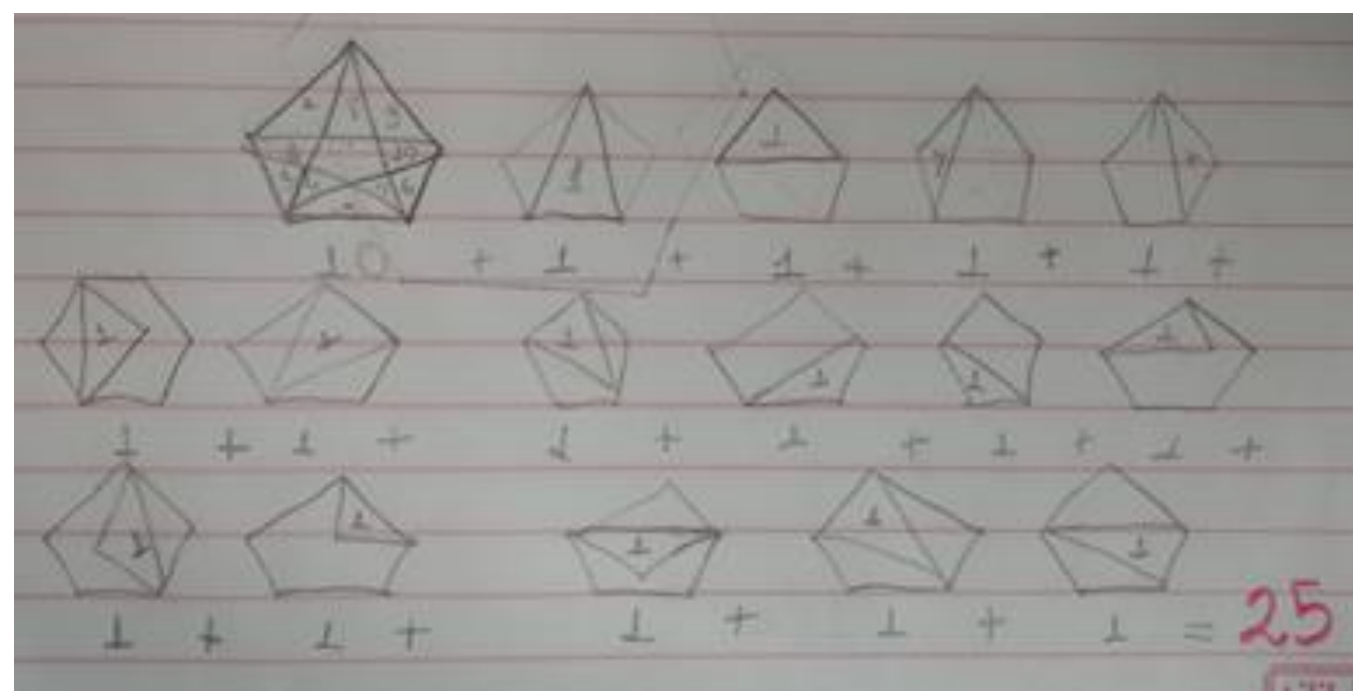

Fonte: Acervo do projeto.

Outra estratégia flagrada, foi aquela utilizada pelo estudante Marcos (figura 6) para auxiliálo na identificação dos triângulos. Ele criou quatro grupos que intitulou de: triângulos pequenos, triângulos médios, triângulos grandes e triângulos gigantes. Nesse caso, o registro do estudante não mostrou de forma clara qual o critério utilizado para considerar um triângulo pequeno, médio, grande ou gigante. Porém, quando questionado, Marcos explicou que os triângulos pequenos não eram formados por outras figuras, os médios eram por duas figuras, os grandes por três figuras e os gigantes por quatro figuras.

Figura 6: Estratégia de registro realizada pelo estudante Marcos

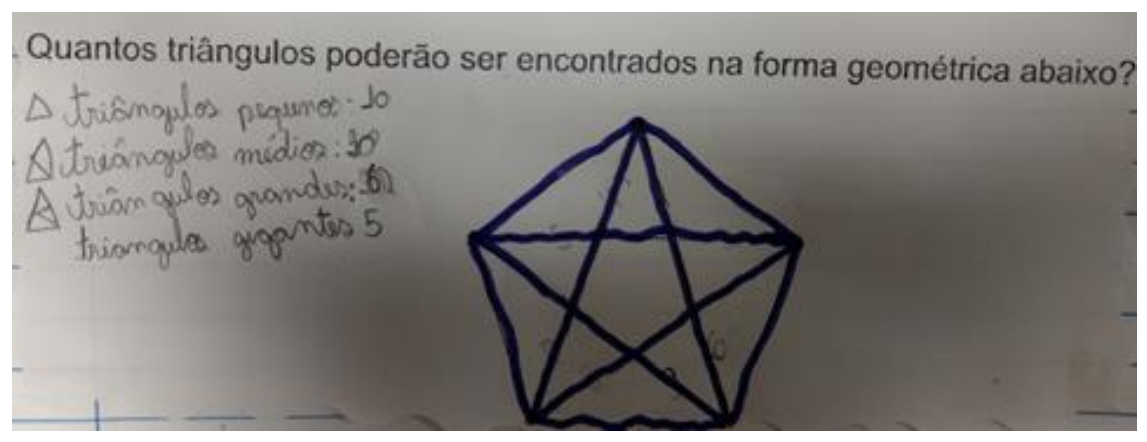

Fonte: Acervo do projeto.

A terceira forma de registro identificada, a nosso ver se assemelhou com a anterior, diferenciando-se no uso mais enfático de auxílio do texto escrito. Davi não apenas mostrou os agrupamentos realizados, mas também relatou a necessidade de rotacionar a folha para visualizar os triângulos e citou que foi "juntando os triângulos", ou seja, ele foi identificando triângulos que 


\section{revemop}

eram compostos. O estudante organizou os triângulos em três grupos, encontrando o total de trinta e dois, como se pode verificar na figura 7.

Figura 7: Estratégia de registro realizada pelo estudante Davi ${ }^{5}$

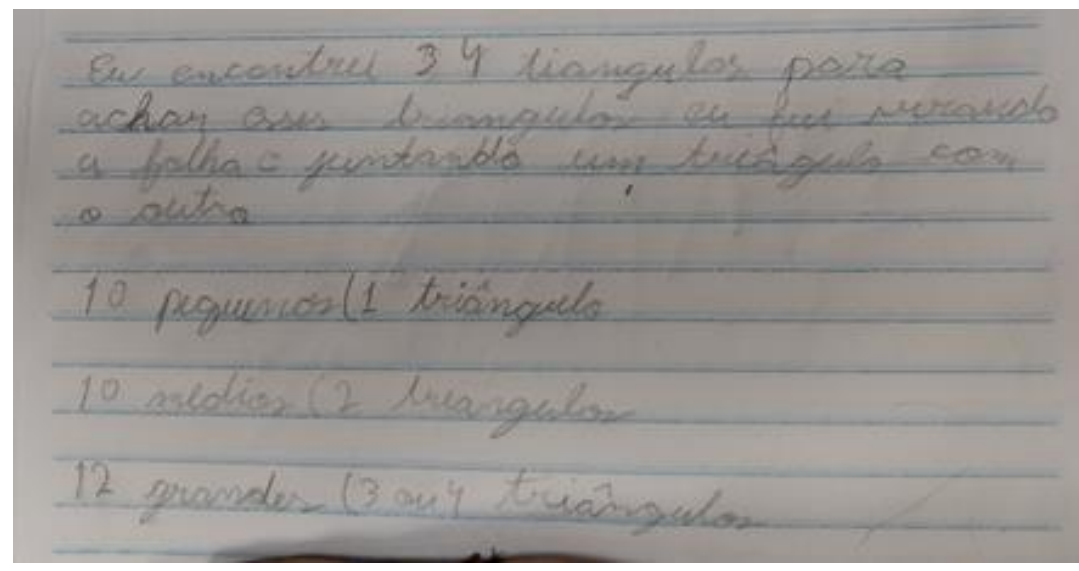

Fonte: Acervo do projeto.

A quarta forma de registro, apresentada na figura 8, mostra que a estudante Helena desenhou treze vezes a figura do enunciado e, no primeiro desenho, considerou os dez triângulos que não eram compostos. No segundo e terceiro desenhos considerou apenas um triângulo. Já nos demais, Helena pensou em termos de categorias, ela destacou um dos triângulos e indicou, abaixo de cada desenho, o total de triângulos que pertenciam à categoria considerada.

Figura 8: Estratégia de registro realizada pela estudante Helena

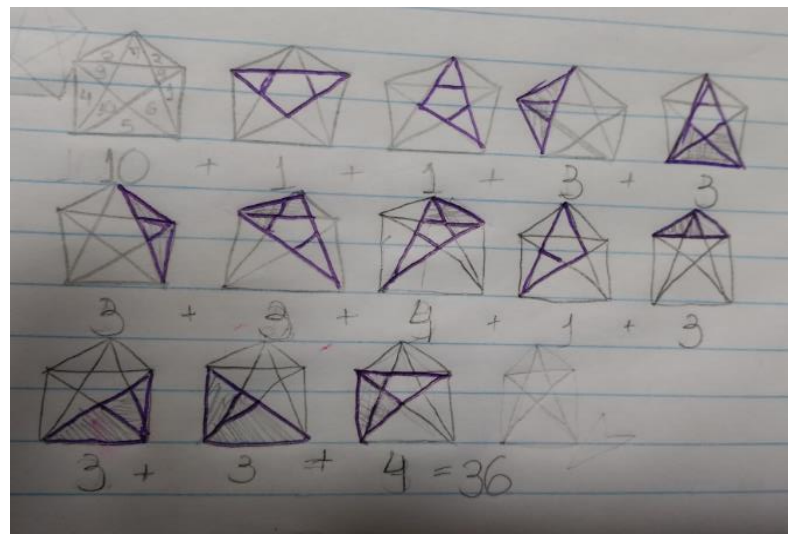

Fonte: Acervo do projeto

O quinto e último registro apresentado neste texto (figura 9), permitiu perceber a estratégia de um discente que localizou sete categorias de triângulos que, juntas, indicaram um total de trinta. Matias utilizou texto escrito e, também, fez desenhos para mostrar os triângulos identificados.

5 Cabe destacar que ele escreveu 34, embora tenha registrado 32. Parece-nos que o 34 representa um equívoco ao realizar as somas parciais. 
Figura 9: Estratégia de registro realizada pelo estudante Matias

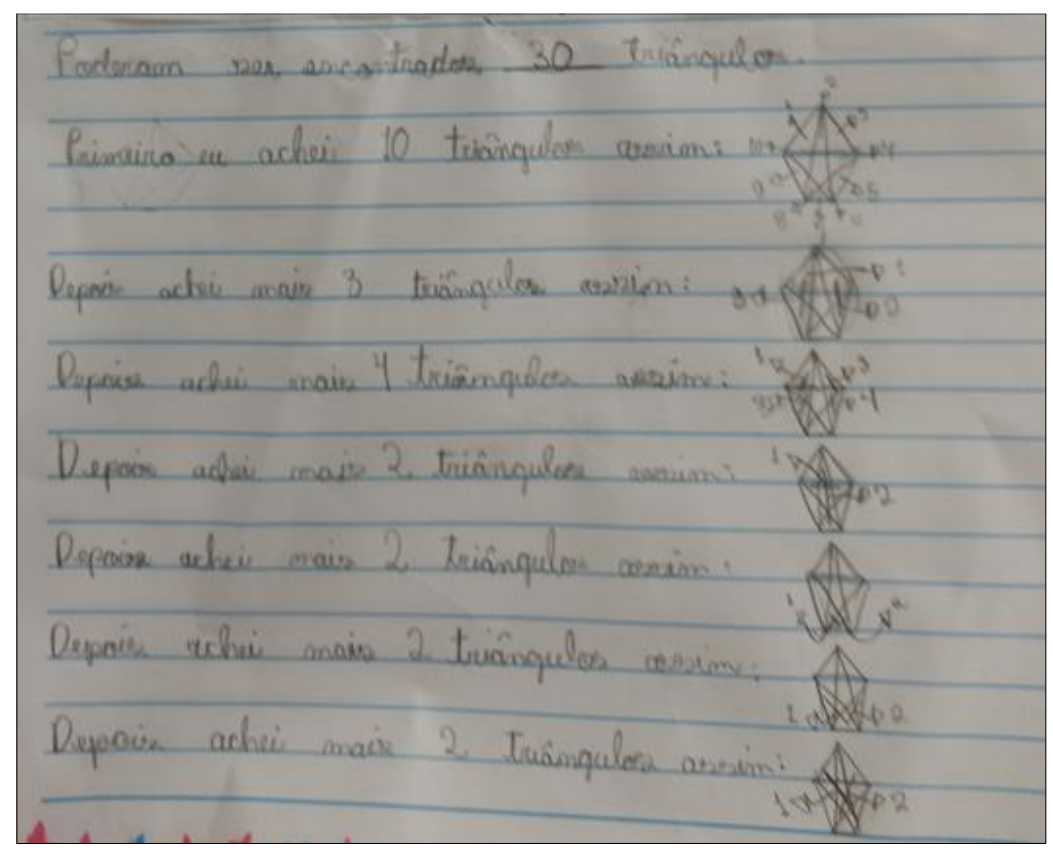

Fonte: Acervo do projeto.

Cabe realçar que durante o compartilhamento das estratégias individuais com o coletivo da sala de aula, percebeu-se que os estudantes ponderaram sobre suas próprias estratégias de resoluções e que, durante a apreciação da solução dos pares, elaboraram explicações sobre 0 que thes parecia colaborar ou não para a solução do problema, se apoiando tanto nos critérios utilizados para fazer os agrupamentos, como nos desenhos.

Na terceira e última aula destinada à resolução do problema, notou-se que embora alguns estudantes ainda apresentassem dúvidas sobre a quantidade total de triângulos, houve um aumento no número daqueles que conseguiram se organizar de forma a encontrar a quantidade total esperada.

Como já era prevista a possibilidade de permanecerem algumas dúvidas, uma estudante da licenciatura em Matemática, que atuava como monitora neste GTD, produziu figuras em cartolina, utilizando cores diferentes, para representar cada um dos tipos de triângulos, como forma de ajudá-los a organizarem a contagem (figura 10). 
Figura 10: Cartolina colorida para auxiliar na contagem dos triângulos

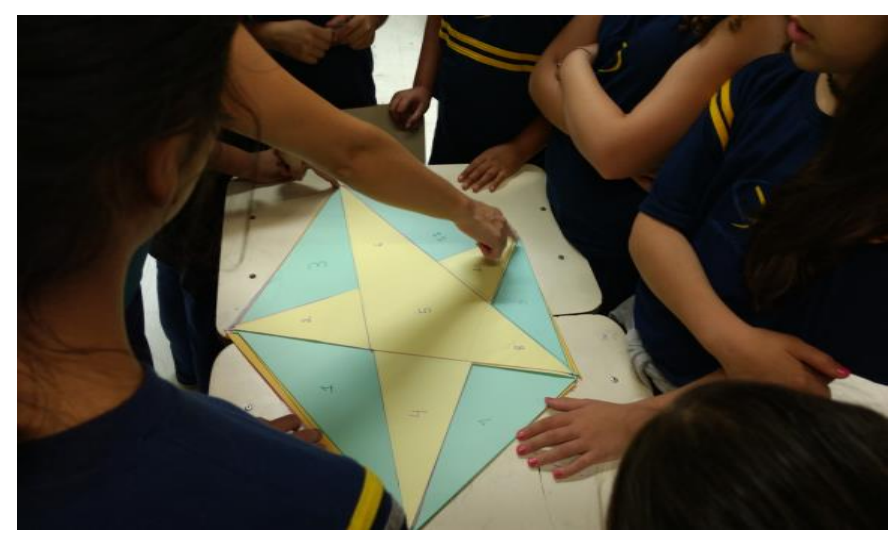

Fonte: Acervo do projeto.

Assim, depois da produção e do compartilhamento de soluções individuais e do uso das cartolinas coloridas, a monitora, com o auxílio dos estudantes, registrou na lousa o número de 35 triângulos, obtidos a partir da contagem considerada correta, conforme mostrado na figura 11.

Figura 11: Registro final na lousa

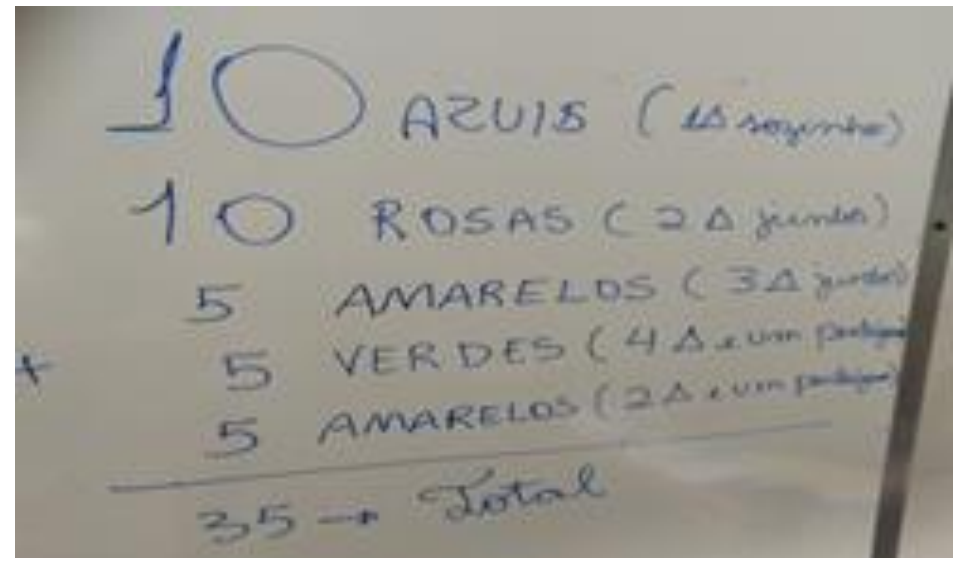

Fonte: Acervo do projeto.

\section{0 papel do registro na atividade 'solução do problema'}

Adotamos como unidade de análise um grupo de três aulas de Matemática, cuja duração total foi de 120 minutos, nas quais identificamos uma atividade. Ao nos debruçarmos sobre 0 material produzido, flagramos momentos que sugerem que os estudantes começaram a desenvolver ações - por exemplo, elaboração de estratégias de registro - na direção de satisfazerem uma necessidade comum, qual seja, resolver o problema 'triângulos no pentágono'. Nesse cenário, vislumbramos a ideia de atividade. Segundo David e Tomaz (2012):

De acordo com Leontiev, a atividade emerge de uma necessidade que dirige os motivos na direção de um objeto. Para satisfazer esses motivos, são necessárias ações. Essas, por sua vez, são realizadas de acordo com as condições que 
determinam a operacionalização de cada ação6 (DAVID E TOMAZ, 2012, p.416, tradução nossa).

Mais especificamente, pensando essa ideia interpretada no modelo triangular de Engeström (2001), consideramos que os estudantes mostraram-se sujeitos da atividade que intitulamos de "resolução do problema triângulos no pentágono". Nessa atividade, como foi possivel notar na descrição apresentada na seção anterior, a comunidade era composta pela professora e por dois monitores do Projeto Descobridores da Matemática.

Em relação às aulas nas quais caracterizamos essa atividade, ressalta-se que quando a professora fez a pergunta norteadora do problema ("Quantos triângulos podem ser encontrados na forma geométrica abaixo"), os discentes responderam rapidamente ("dez") considerando que já tinham obtido a resposta correta. Contudo, a professora, investida pela autoridade que aquela comunidade nela reconhecia, agiu provocando os estudantes, ao informar que eles estavam enganados ("existem mais triângulos"). Essa ação da docente pareceu ter sido um dos fatores que colaborou para a emergência de uma necessidade coletiva naquele grupo de estudantes. Tal cenário, ganhou visibilidade, em dois vértices da base social do modelo triangular. Nota-se, em um deles (a divisão de trabalho), que competiu à professora e aos monitores que participavam desse (sigla da disciplina) o papel de organizar as propostas pedagógicas e, também, a ela coube legitimar ou não as respostas dos estudantes.

A impressão de que os estudantes começaram a se mobilizar no sentido de satisfazer uma necessidade coletiva, se evidenciou quando, na segunda aula, ao retomar a discussão do problema, a professora os encontrou interessados em compartilhar com os pares, com ela e, também, com os monitores as 'novas soluções' encontradas.

Importa-nos ponderar, de um lado, que reconhecemos que a busca dos discentes por soluções para o problema dos triângulos, nesse momento inicial, explicava-se, em parte, pelo fato da situação ter ficado como 'dever de casa', ou seja, parece plausível supor que eles se esforçaram para cumprir uma das regras estruturantes daquela comunidade. De outro lado, consideramos igualmente plausível supor que 'só' essa regra não explica os diferentes retornos trazidos pelos estudantes; consideramos que, além dela, os estudantes buscaram soluções porque se sentiram desafiados pela professora a - e compromissados com seus pares em - encontrar os 'triângulos

6 According to Leont'ev, activity emerges from a necessity, which drives motives towards a related object. To satisfy motives, actions are needed. These, in turn, are accomplished in accordance with the conditions that determine the operations related to each action. 


\section{revemop}

a mais' (informados pela professora). Ou ainda, nos termos de Allevato (2005) porque a questão proposta de fato foi interpretada pelos discentes como um problema, tanto porque os alunos não conheciam os meios necessários para resolvê-la, quanto porque eles se mostraram interessados em resolvê-la.

Tais afirmações sobre a relação dos estudantes com esse problema se sustentam na constatação empírica de que eles não se intimidaram pelos diferentes números de triângulos que encontraram - quando trouxeram para sala de aula soluções parciais desenvolvidas em suas casas -, mas, ao contrário, começaram a trabalhar juntos para analisar se as diferentes soluções produzidas pelos pares pareciam coerentes.

Assim sendo, sintetizamos esse cenário que construímos à luz da THCA, na figura 12, apresentada a seguir.

Figura 12: Atividade 'resolução do problema da contagem dos triângulos'

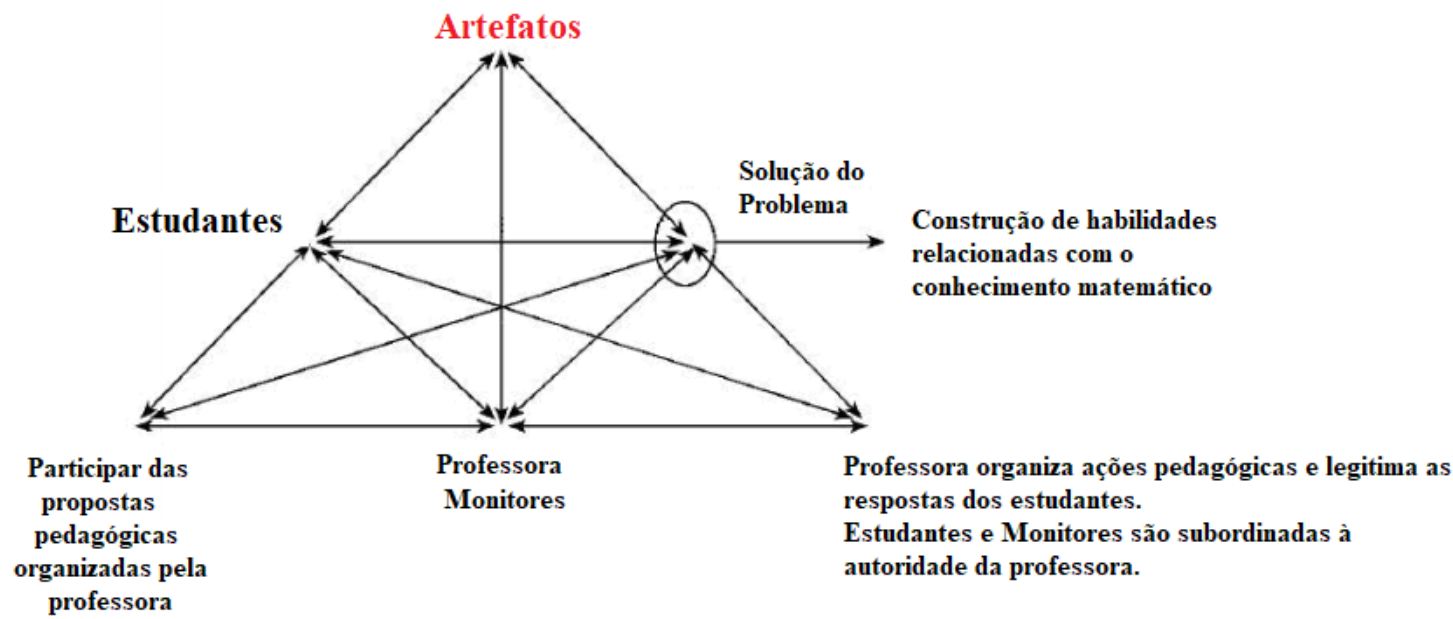

Fonte: Adaptação do modelo triangular de Engeström (2001, p.135).

Com esse modelo não só sintetizamos a unidade analisada como, intencionalmente, destacamos (em vermelho) o componente no qual concentramos mais atenção nessa análise, qual seja: o componente artefatos. Essa atenção, não ingênua, emergiu do material empírico produzido. Nesse material, percebemos que quando os estudantes passaram a ponderar coletivamente sobre suas estratégias, os registros que eles elaboraram começaram a ganhar visibilidade. Pois, quando socializaram suas soluções com a turma, eles mesmos perceberam que haviam contados triângulos repetidos, além de não considerar todos os triângulos presentes no problema. Ainda na socialização das soluções, mais especificamente, foi possível notar que eles identificaram a duplicidade de marcações que fizeram em um dos registros apresentados (figura 04).

Cabe destacar que, em detrimento de criticar os registros produzido pelos discentes, a 
professora e os monitores, atuaram de forma que os estudantes passassem a perceber que o uso de registro podia ser útil, mas que precisavam pensar em formas de deixá-los suficientemente organizados para que eles próprios não se confundissem no processo de identificação dos triângulos. Destaca-se ainda que não foi definido "um" registro como "o" melhor, mas as aulas foram conduzidas de forma que os estudantes desenvolvessem formas de registro que a eles parecessem mais organizadas e que contribuíssem para a solução do problema.

Consideramos, pois, que essa troca entre a professora, monitores e os estudantes, colaborou para os alunos se apropriarem dos registros elaborados, transformando-os em artefatos de mediação. Torna-se necessário ressaltar que esse processo de apropriação revelou não só um 'apego' de muitos estudantes ao artefato por eles produzido, mas também que tais discentes resistiram em adequá-lo quando o coletivo apontou nele fragilidades. Todavia, com a insistência dos pares e com pequenas interferências da professora, os discentes foram resistindo menos e percebendo que outros artefatos possibilitavam uma melhor identificação das duplicidades e do número maior de triângulos; além disso, também mostraram potencial para ajudá-los a elencar os triângulos identificados. Em outros termos, os discentes foram percebendo, coletivamente, que 0 aprimoramento dos registros colaborava para que se aproximassem de seu objeto de desejo (a solução do problema).

Em relação a esse aprimoramento dos registros, alguns destaques parecem-nos necessários de serem pontuados. Um primeiro destaque ganhou visibilidade quando comparamos as figuras 4 (quatro) e 5 (cinco). Se, na quatro, foi possível perceber que a estratégia de contornar o desenho não possibilitou uma visualização clara de cada triângulo identificado, na figura 5 , a estratégia de desenhar cada um dos triângulos que foi localizado, passou a possibilitar a visualização e identificação de quase todos eles.

Destacamos ainda, ao compararmos os registros evidenciados nas figuras 4 (quatro), 6 (seis) e 7 (sete), que a estratégia de apenas contornar os triângulos que constavam no enunciado do problema (figura quatro) foi sendo abandonada por alguns estudantes, a partir das trocas de informação coletivas, uma vez que eles perceberam que, com ela, se perdiam no processo de contagem. Outros estudantes (figuras 6 e 7), continuaram, pois, fazendo os contornos, porém, para diminuir o risco de duplicidade ou esquecimento, criaram categorias. Destaca-se ainda que no registro da figura 7, além das categorias foi explicitado o critério utilizado no agrupamento. Nesse sentido, percebemos um aprimoramento do registro mostrado nas figuras 6 e 7 , quando comparado com a 4.

Além disso, ao observar os registros desvelados nas figuras 8 e 9 , pudemos notar que os 


\section{revemop}

estudantes criaram categorias de triângulos e, também, usaram representações visuais dos triângulos de cada categoria. Assim, pode-se perceber que o uso de representações visuais auxiliou na organização da informação em estruturas que favoreceram a busca de uma solução analítica do problema.

Esse aprimoramento dos registros transformando-os, talvez, em artefatos mais complexos (IMPEDOVO; ANDREUCCI e GINESTIÉ, 2017) pareceu evidenciar que os estudantes foram percebendo que a contagem era facilitada quando o registro possibilitava: i) visualizar os triângulos e ii) categorizar os triângulos em grupos, evidenciando o critério utilizado na classificação. Embora, aparentemente, tal fato tenha sido percebido pelos discentes, explicitamos que, não houve um momento em que identificamos o desenvolvimento de um 'registro ótimo', ou seja, um registro que os conduzisse ao total dos 35 triângulos, portanto, à solução do problema. Todavia, nos pareceu que, quanto mais o registro se aproximou dessas duas características, mais perto os estudantes chegaram da solução (figura 11).

A solução só foi alcançada na última aula, quando um dos monitores produziu um artefato auxiliar (pentágono e triângulos em material concreto) que, a nosso ver, se somou ao artefato registro, e colaborou para os estudantes, como coletivo, alcançarem o objeto dessa atividade.

\section{Considerações Finais}

Organizamos este artigo com objetivo de analisar como diferentes formas de registro, utilizadas por estudantes do quinto ano do Ensino Fundamental, poderiam contribuir para a construção da solução de um problema. Para que a mencionada análise fosse empreendida, nos ancoramos teórico-metodologicamente na Teoria Histórico-Cultural da Atividade (ENGESTRÖM e SANNINO, 2010; LEONTIEV, 1978).

Com tal lente de análise, nos debruçamos sobre um relatório produzido por monitores do projeto Descobridores da Matemática, orientados por uma das autoras deste artigo, no qual havia a solução comentada do problema intitulado 'triângulos no pentágono'. A partir desse movimento, empreendemos uma análise que revelou que os estudantes por diferentes razões desafio do problema proposto, intervenções assertivas da professora e dos monitores, ambiente de sala de aula favorável à comunicação de ideias - se uniram, dando um sentido coletivo para a busca da solução do problema que envolveu a identificação de triângulos. Tal situação permitiu que um conjunto de aulas de Matemática fosse interpretado como uma atividade coletiva. 
Ao colocar a lente de análise 'nessa busca', notamos que os estudantes foram criando e aperfeiçoando diferentes tipos de registro. Eles, nesse percurso, fizeram com que os registros avançassem de uma simples estratégia de síntese para um artefato capaz de ajudá-los a lidar com os percalços que apareceram no processo de resolução - sobretudo, duplicidade ou esquecimento de triângulos, na contagem.

Se, de um lado, foi possivel perceber essa ressignificação dos registros, de outro, também percebemos que ela não excluiu a demanda por utilizar outros tipos de artefatos, na mediação da relação dos estudantes com a solução do problema. Por exemplo, em certo momento da aula, houve a necessidade de fazer uso de material concreto (recortes de cartolinas coloridas) para visualização dos triângulos, na organização final da solução encontrada pelo coletivo de estudantes.

Destacamos, a partir dessa análise, que o registro não foi apenas uma 'tarefa arbitrária' imposta pela professora - como temos percebido, muitas vezes, em nossa trajetória como docentes e pesquisadores. A questão é que a resolução do problema demandou o uso do - e foi facilitada pelo - registro e, portanto, esse passou a ter sentido para os estudantes. Tal fato, a nosso ver, permite afirmar que caso seja intenção dos professores levar os estudantes a construírem um repertório de registros durante a resolução de problemas, é fundamental que sejam planejadas situações que, assim como a apresentada, despertem, nos estudantes a necessidade de registrar.

Destacamos ainda que um planejamento de situações dessa natureza é uma importante função que o professor pode assumir. Ressaltamos, contudo que não se trata somente de selecionar problemas 'adequados', mas, sim, prever a criação de um ambiente em sala de aula que incentive a socialização, a argumentação, a discussão de ideias, privilegiando, sempre que possivel, as diferentes formas de registros produzidas pelos discentes.

Consideramos, por fim, que as elaborações decorrentes desta investigação, sugerem que outras pesquisas são necessárias para aprofundar reflexões em torno de questões como: Quais ações professoras e professores podem realizar para identificar e valorizar artefatos produzidos pelos estudantes durante a resolução de um problema? Que características devem conter os problemas para possibilitar o desenvolvimento de artefatos de mediação? Consideramos também que quando os professores, de um lado, planejam (DEODATO, 2020) aulas que preveem a resolução de problemas e, de outro, o fazem em um ambiente marcado pelas características antes destacadas, eles podem não só contribuir para o desenvolvimento de processos de aprendizagem matemática pelos discentes - como recolher, classificar, registrar, organizar dados 
- caros para a aprendizagem das mais diferentes áreas da matemática escolar, dentre as quais a geometria; mas também podem colaborar para a formação de estudantes ativos, 'descobridores' de uma matemática diferente daquela reconhecida por muitos como um conjunto de regras arbitrárias.

\section{Referências Bibliográficas}

ALLEVATO, Norma Suely Gomes. Associando o computador à resolução de problemas fechados: análise de uma experiência. 2005. 378p. Tese (Doutorado em Educação Matemática) - Instituto de Geociências e Ciências Exatas, Universidade Estadual Paulista. Rio Claro.

CAMPOS, llaine Silva. A Divisão do Trabalho no ambiente de aprendizagem de Modelagem Matemática segundo a Educação Matemática Crítica. 2018. 255p. Tese (Doutorado em Educação) - Faculdade de Educação, Universidade Federal de Minas Gerais. Belo Horizonte.

CAMPOS, Camila Amorim; SOUZA, Marília Rodrigues Alves de; SILVA, Daniel Jacinto da. Dicionário Científico llustrado. Interfaces-Revista de Extensão da UFMG, v. 8, p. 133-143, 2020.

COLE, Michael. Cultural psychology: A once and future discipline. Cambridge: Harvard University Press, 1996.

COSTA, Jorge Luis. Atividades docentes de uma professora de Matemática: artefatos mediadores na EaD. 2016. 214p. Tese (Doutorado em Educação) - Faculdade de Educação, Universidade Federal de Minas Gerais. Belo Horizonte.

DALTO, Jader Otavio; SANTOS, João Ricardo Viola dos; BURIASCO, Regina Luzia Corio de. Multiplicidades de resoluções de alunos do ensino médio em problemas abertos de matemática. Revista Brasileira de Estudos Pedagógicos, v. 98, n. 248, p. 110-129, 2017.

DAVID, Maria Manuela; TOMAZ, Vanessa Sena; FERREIRA, Maria Cristina Costa. How visual representations participate in algebra classes mathematical activity. ZDM, v. 46, n.1, p. 95-107, 2014.

DAVID, Maria Manuela; TOMAZ, Vanessa Sena. The role of visual representations for structuring classroom mathematical activity. Educational Studies in Mathematics, v. 80, n.3, p. 413-431, 2012.

DEODATO, André Augusto. Articulação entre disciplinas de uma escola de tempo integral: reverberações de um "Grupo de Trabalho Diferenciado (GTD)" nas aulas de Matemática. 2017. 209p. Tese (Doutorado em Educação) - Faculdade de Educação, Universidade Federal de Minas Gerais. Belo Horizonte.

DEODATO, André Augusto. Experiências no Planejamento da Disciplina Prática do Ensino Médio I. Revista Brasileira de Ensino de Ciências e Matemática, v. 3, n. 2, 28 jul. 2020.

ENGESTRÖM, Yrjö.; SANNINO, Annalisa. Studies of expansive learning: Foundations, findings and future challenges. Educational Research Review, v. 5, n. 1, p. 1-24, 2010. 
ENGESTRÖM, Yrjö. Expansive learning at work: toward an activity theoretical reconceptualization. Journal of Education and Work, v.14, n.1, p. 133-156, 2001.

IMPEDOVO, Maria Antonietta; ANDREUCCI, Colette; GINESTIÉ, Jacques. Mediation of Artefacts, Tools and Technical Objects: an international and French perspective. International Journal of Technology Design Education, v.27, p.19-30, 2017.

LEONTIEV, Alexei Nikolaevich. 0 desenvolvimento do psiquismo. Tradução de Newton Duarte. Lisboa: Livros Horizonte, 1978.

LOPES, Celi Espasandin. Educação estatística no curso de licenciatura em matemática. Bolema: Boletim de Educação Matemática, v. 27, n. 47, p. 901-915, 2013.

LOPES, Anemari Roesler Luersen Vieira; MARCO, Fabiana Fiorezi de. Pesquisa em Educação Matemática e Psicologia Histórico-Cultural: alguns apontamentos. Educação Matemática Pesquisa, v. 17, n. 3, p. 456-471, 2015.

RESENDE, Tânia Freitas. Dever de casa, espelho de desigualdades educacionais e sociais. Educação em Revista, v. 28, p. 159-184, 2012.

SOUSA, Luciana Pereira de. Contradições na atividade de trabalho das professoras dos anos iniciais em uma escola do estado do Tocantins. 2020. 210p. Tese (Doutorado em Educação) - Faculdade de Educação, Universidade Federal de Minas Gerais. Belo Horizonte.

SOUTO, Daise Lago Pereira. Transformações Expansivas em um curso de Educação Matemática a Distância Online. 2013. 281p. Tese (Doutorado em Educação) - Instituto de Geociências e Ciências Exatas, Universidade Estadual Paulista Júlio de Mesquita Filho. Rio Claro. 